\title{
THE INFLUENCE OF RUNNING WIDE ON THE BEND ON FINISHING TIMES AND POSITIONS IN MEN'S AND WOMEN'S 800 M FINALS AT MAJOR GLOBAL CHAMPIONSHIPS
}

\author{
Fernando González-Mohíno, ${ }^{1,2}$, Arturo Casado ${ }^{3}$, Andrew Renfree ${ }^{4}$, \\ José María González-Ravé 1 , and Brian Hanley ${ }^{5}$ \\ ${ }^{1}$ University of Castilla-La Mancha, Faculty of Sport Science, Sport Training Laboratory, Spain \\ ${ }^{2}$ Universidad Nebrija, Facultad de Ciencias de la Vida y de la Naturaleza, Spain \\ ${ }^{3}$ Center for Sport Studies, Rey Juan Carlos University, Madrid, Spain \\ ${ }^{4}$ University of Worcester, School of Sport \& Exercise Science, UK \\ ${ }^{5}$ Leeds Beckett University, Carnegie School of Sport, UK
}

Original scientific paper

DOI $10.26582 / \mathrm{k} .53 .2 .13$

\begin{abstract}
:
The aim of this study was to determine the influence of running wide on bends regarding intermediate changes of position, dispersion of athletes, and speed relative to season best (SB) between medalists and non-medalists in men's and women's 800 m championship finals. Extra distance covered on bends was measured using official videos. The total distance run was calculated and described as the minimum calculable distance. Theoretical mean speeds, theoretical finishing times and theoretical finishing positions were calculated. In addition, intermediate and total changes of position (on bends and straights) and dispersion between athletes in each 100-m segment were calculated. Finishing times and segment times were calculated relative to SB. Theoretical finishing times were faster than official finishing times $(p<.001)$. Finishing positions were influenced by extra distance covered. Medalists displayed a higher number of positive changes of intermediate positions than non-medalists $(\mathrm{p}<.001)$, occurring mainly on the straights $(\mathrm{p}=.003)$ and were greatest between 500 and $600 \mathrm{~m}(\mathrm{p}=.003)$, without differences between groups in total extra distance and in extra distance covered on each bend. Medalists displayed higher total speeds relative to SB $(p=.042)$ and over the 500-600 m segment onwards $(\mathrm{p}<.05)$, increasing the dispersion from this segment onwards $(\mathrm{p}<.001)$. These findings indicate that running the shortest distance on the bends and being able to accelerate during the last $300 \mathrm{~m}$ of the race positively influence finishing position in major championships $800 \mathrm{~m}$ finals.
\end{abstract}

Key words: athletics, pacing, middle-distance running, performance

\section{Introduction}

Success in competitive middle-distance running requires an appropriate strategic and tactical decision-making, related to both one's own running speed and race position relative to competitors (Casado \& Renfree, 2018; Hanley, Stellingwerff \& Hettinga, 2019). The $800-\mathrm{m}$ event is a short middle-distance race with multiple competitors (typically eight in major championship events) and tactical behaviors are thus a key determinant of race outcome. Decision-making within a race context is influenced by a complex array of factors specific to both the individual athlete (Renfree, Martin, Micklewright \& St Clair Gibson, 2014) and the characteristics of the environment in which they are competing (Renfree \& Casado, 2018).
Fast times in the event are associated with positive pacing profiles with a faster first lap, although occasionally negative splits (where the second lap is quicker than the first) are observed during tactical races at major championships where a fast finishing time is not the primary objective (Casado, Hanley, Jiménez-Reyes \& Renfree, 2020). Tactical decisions in major championship races are therefore based on aiming to achieve a high finishing position, and include strategies related to pacing and positioning. Behaviors such as drafting to reduce air resistance and attempting to run the shortest distance on the bends are examples of tactics used to try to reduce total energy cost but could increase the likelihood of getting "boxed in", whereby the athlete is blocked by other athletes and unable to 
respond to changes in pace made by his/her rivals (Martin \& Coe, 1997). Running wide of the inside of the track helps avoid being boxed in but increases a total distance run; for example, the eventual silver medalist at the Olympic Games in 2000 produced a faster mean speed than the winner but ran a greater total distance on the bends due to poor tactical and positional decision-making (Jones \& Whipp, 2002). For this reason, athletes in a longer middle-distance event of the 1500-m tended to increase pace on the straights rather than the bends (Aragón, Lapresa, Arana, Anguera \& Garzón, 2016). Because of the very small differences in finishing times between qualifiers and non-qualifiers to the next round in preliminary heats, or between medalists and nonmedalists in finals (Hanley \& Hettinga, 2018), it is necessary to highlight to coaches the need to optimize their athletes' tactical approaches during major championships.

Poor tactical decision-making means that some athletes cover extra distance to move up positions or stay close to the leaders of the race, making the $800-\mathrm{m}$ race a complex event, partially determined by the intermediate positioning relative to the opponents that could result in athletes needing to cover greater distances than their rivals. Previous studies showed that tactical positioning at intermediate stages of the race was a deciding factor in finishing position in the 800-m events at the 2012 Olympic Games and 2017 IAAF World Championships (Renfree, Mytton, Skorski \& St Clair Gibson, 2014; Casado \& Renfree, 2018). These authors found that more successful runners generally took the lead early in the race and maintained these higher intermediate positions during $800-\mathrm{m}$ major championships. Thus, whether staying within the leading intermediate positions throughout the race to achieve a successful finishing position could involve either increasing or decreasing total distance covered and, in turn, performance, has not been elucidated yet.

Furthermore, the dispersion (distance between them) between athletes and the difference between lap times were important determinants of the finishing position in global championships (GonzálezMohíno, Santos del Cerro, Renfree, Yustres \& González-Ravé, 2020). By presenting absolute performances achieved (finishing times) relative to the season's best performance (SB), it is possible to estimate the relative performance recorded (Casado $\&$ Renfree, 2018). Previous analyses of tactical behaviors at major championship events found no difference in the relative performance recorded by qualifiers and non-qualifiers from preliminary heats (Renfree, Mytton, Skorski \& St Clair Gibson, 2014; Casado \& Renfree 2019). Analysis of finishing times in track flat races during major championship has demonstrated that finals are slower than
SBs before the championship (Casado, Renfree, Maroto-Sánchez \& Hanley, 2020) and reiterates the prioritization of finishing position ahead of finishing time in world-class athletes. Regarding the differences in speed per segments of medalists and non-medalists during major championships finals, medalists displayed higher absolute speeds compared to non-medalists from 500-m onwards (Hanley, Stellingwerff, \& Hettinga, 2019). Therefore, establishing finishing times in relation to the SB is important in establishing whether the athletes have performed closer to their potential in the final, and whether the fastest athletes during the season are more likely to obtain higher final positions.

No previous studies have taken into account the influence of overtaking or covering extra distance on the bends on the eventual race outcome. It seems reasonable to suggest that the greater the extra distance covered on the bends, the greater the impact on the finishing position. Therefore, the first part of the study aims to determine the influence of running wide on bends on the race outcome during the IAAF World Championship and Olympic Games 800-m finals. In addition, some athletes could cover more extra distance on the bends but gain position, and therefore doing so would not be detrimental to their finishing position. Therefore, the second part of the study aims to analyze the influence of changes in position, distance between athletes (dispersion) and speed relative to SB between the medalists and non-medalists in men's and women's 800-m racing at global championships. We hypothesized that running wide on the bends affected finishing positions, that the medalists covered less distance than the non-medalists on the bends, and that the medalists would gain positions. Moreover, we hypothesized that the medalists would display higher relative speeds than the non-medalists in the last 300-400-m and would increase the dispersion between them, which would result in more changes of positions by the medalists because of the acceleration in race pace, whereas the non-medalists would not be able to maintain the race pace.

\section{Methods}

\section{Participants}

The men's and women's 800 -m final races at two World Championships [WC] (Moscow in 2013 and London in 2017) and one summer Olympic Games [OG] (Rio de Janeiro in 2016) were analyzed. Eight athletes were analyzed in each of the men's and women's 800 - $\mathrm{m}$ final races ( $\mathrm{n}=48$ performances). Official 100-m segment times at both WCs and OG were obtained from the open-access World Athletics website. All data are freely available in the public domain; therefore, no ethics committee approval was necessary for this study. 


\section{Design and procedures}

The study quantified the extra distance covered on the bends by athletes at the global championships (WC and OG). To measure the extra distance covered by the athletes on bends, official videos of the championships were analyzed. Videos were downloaded via YouTube and analyzed on Kinovea ${ }^{\circledR}$ software using a frame-by-frame method, previously validated and with a measurement error of $0.02 \mathrm{~s}$ (Mytton, et al., 2015). A 400-m track features two equal bends and two parallel straights. Lane 1 is measured $0.30 \mathrm{~m}$ from the outer edge of the inside kerb, whereas in all other lanes the distance run is measured $0.20 \mathrm{~m}$ from the outer edge of the inside lane marking. The distance involved in completing one lap is the length of the straights plus, for the bends, $2 \pi \mathrm{r}$ (lane width $=1.22 \mathrm{~m}$ ). Thus, an athlete runs $407.04 \mathrm{~m}$ per lap in lane 2 rather than 400 $\mathrm{m}$ on the rail in lane 1 (Jones \& Whipp, 2002). Three zones (outside lane 1, lane 2 and lane 3 ) were observed and the time the athletes spent running in each zone while on the bends was measured (Figure 1); on no occasion did an athlete run any wider than lane 3. Two experienced researchers quantified the time the athletes spent in each of these zones. These times were expressed as a percentage of the $100-\mathrm{m}$ split time of each athlete. Athletes' split times were used to calculate mean speed during each $100-\mathrm{m}$ segment. The first $100-\mathrm{m}$ segment $(0-100 \mathrm{~m})$ was ignored from the calculation as it is an allocated lane in the 800-m event. Once the $100-\mathrm{m}$ split was completed, the time spent in each zone was multiplied by $1.76 \mathrm{~m}, 3.52 \mathrm{~m}$ and $7.04 \mathrm{~m}$ (for outside lane 1, lane 2 and lane 3), respectively, and the extra distance of each 100-m split was added. For example, an athlete with a 100-m split time of $15 \mathrm{~s}$ on a bend who ran $5 \mathrm{~s}(33 \%)$ in the outside of lane 1 and the rest of the time $(10 \mathrm{~s}$, $67 \%$ ) in lane 2 was considered to have run $102.9 \mathrm{~m}$

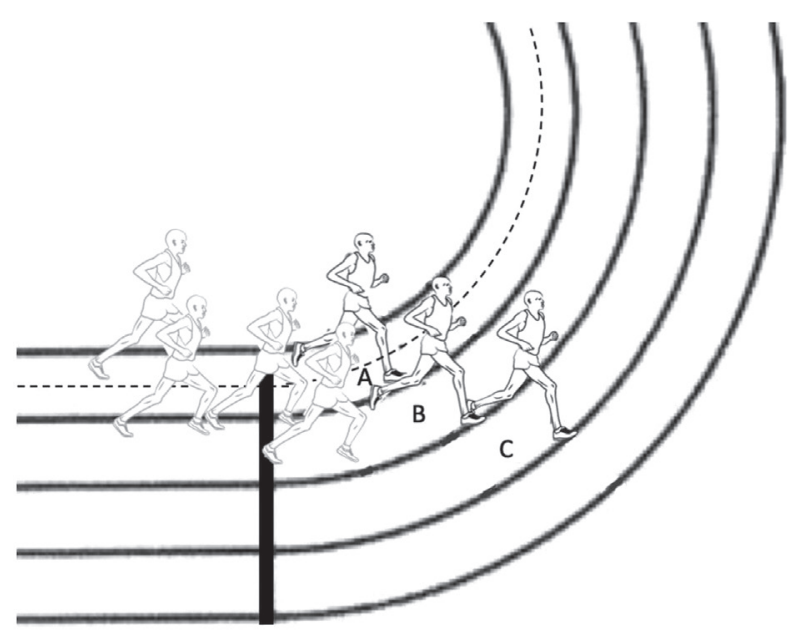

Figure 1. Graphical representation indicating the zones used to measure the extra distance covered on bends every $100 \mathrm{~m}$ (based on official race distance) run: $A(1.76 \mathrm{~m}), B(3.52 \mathrm{~m})$ and $C(7.04 \mathrm{~m})$. on that bend. In all the competitions analyzed, a 400-m standard track was used, which has a radius of $36.5 \mathrm{~m}$, bends of length $115.51 \mathrm{~m}$, and straights of length 84.39 m (Aftalion \& Martinon, 2019; World Athletics, 2019). For that reason, our calculations are made for each 100-m segment and the extra distance in the straight $100-\mathrm{m}$ segments have approximately $15 \mathrm{~m}$ of a bend included.

The total distance run was calculated for each athlete, based on the video analysis and accounting for extra distance run on the bends, and has been described as the minimum calculable distance. This distance was considered the 'minimum calculable' as it was not possible to account for all slight movements made by the athletes (e.g., if moving from the inside of lane 1 to its outside on the straights). Based on these values, we calculated the theoretical mean speed (the official race time divided by the minimum calculable distance), theoretical finishing time (the official race distance divided by the theoretical mean speed) and theoretical finishing position (where the athletes would have finished had they all achieved their theoretical finishing times).

In addition, intermediate positions were available at each $100-\mathrm{m}$ point (from 200-m onwards). With these data, changes of position in each $100-\mathrm{m}$ segment and total changes in race position (on bends and straights) were calculated. Positive values indicate net gains in position (overtaking), and negative values indicate net loss of position.

To establish the dispersion of the athletes during each intermediate segment (each 100-m), standardized scores (SS) of speeds for each 100-m segment were calculated using the same methods as in the study by González-Mohíno et al. (2020) as follows:

$$
S S=\frac{\text { Individual speed }- \text { mean speed of the race }}{\text { Standard deviation of the race speed }}
$$

A value of 0 indicates that the individual speed and the mean speed of all the athletes in that race remains the same. Positive values indicate that the athlete's speed is higher than the group mean, and negative values indicate the opposite. Finishing times and each segment times (from 200-m onwards) were calculated relative to SB performances recorded before the championships. Finally, the sample was divided into medalists (top three finishing positions) and non-medalists $\left(4^{\text {th }}-8^{\text {th }}\right.$ finishing positions).

\section{Statistical analysis}

The data are presented as means and standard deviations (SD). An unpaired $t$-test was used to identify significant group (medalists $v s$. non-medalists) differences. A paired samples $t$-test was used to test for statistical differences between the official and theoretical finishing times. Statistical significance was set at $\mathrm{p}<.05$ and $95 \%$ confidence intervals (95\% 
CI) for mean differences were also calculated. Effect sizes were calculated using Cohen's $d$ (Cohen, 1988) and considered to be either trivial $(d<0.20)$, small $(0.21-0.60)$, moderate $(0.61-1.20)$, or large $(1.21$ - 2.00) (Hopkins, Marshall, Batterham. \& Hanin, 2009). Pearson product-moment correlations $(r)$ were used to assess relationships between the final positions and the dependent variables.

\section{Results}

The official finishing times, intermediate positions and mean speed for each men's and women's final with the minimum calculable distance, theoretical speed and theoretical finishing times and positions in the $800-\mathrm{m}$ event are presented in Table 1. Overall, the theoretical finishing times were faster in these 800-m races than the official finishing times by $0.40 \pm 0.33 \mathrm{~s}$ and $0.41 \pm 0.35 \mathrm{~s}$ for men and women, respectively $(\mathrm{p}<.001)$, but the effect sizes were trivial for men $(d=0.03)$ and small for women $(d=0.30)$. On the bends, men and women covered a mean extra distance of $0.41 \pm 0.65 \mathrm{~m}$ and $0.41 \pm 0.60$ $\mathrm{m}$ per bend, respectively, whereas for each straight the mean extra distances run were $0.07 \pm 0.13 \mathrm{~m}$ and $0.06 \pm 0.13 \mathrm{~m}$ for men and women, respectively.
Table 2 describes the comparisons between the medalists and non-medalists in changes of intermediate positions, extra distance and standardized score of speed. The medalists displayed a higher number of positive changes of intermediate positions than the non-medalists $(p<.001)$. These positive changes of intermediate positions in the medalists occurred mainly on the straights $(\mathrm{p}=.003)$. In addition, the differences in changes in intermediate positions between the medalists and nonmedalists were greatest between 500 and $600 \mathrm{~m}$ $(\mathrm{p}=.003)$, with no differences in the other segments. No differences were found between the groups in total extra distance and in extra distance covered on each bend. Regarding the dispersion of athletes, the non-medalists ran faster than the medalists in the 200-300-m segment ( $p=.031)$, and the medalists ran faster than the non-medalists over the 500-600 $\mathrm{m}$ segment onwards $(\mathrm{p}<.001)$.

Table 2 also describes the comparisons between the medalists and non-medalists in segment speed relative to the SB speed. The medalists displayed higher speeds relative to the SB speed $(\mathrm{p}=.042)$ compared with the non-medalists. Furthermore, the medalists displayed higher speeds relative to

Table 1. Minimum calculable distance, theoretical speed and finishing time, and positions for the $800 \mathrm{~m}$ event at the 2013 and 2017 IAAF World Championships and 2016 Olympic Games

\begin{tabular}{|c|c|c|c|c|c|c|c|c|c|c|c|c|c|c|c|}
\hline \multirow[t]{2}{*}{$\begin{array}{l}\text { Finishing } \\
\text { race } \\
\text { position }\end{array}$} & \multicolumn{3}{|c|}{ Finishing time (min:s) } & \multicolumn{3}{|c|}{$\begin{array}{l}\text { Minimum calculable } \\
\text { distance }(\mathrm{m})\end{array}$} & \multicolumn{3}{|c|}{ Theoretical speed (m/s) } & \multicolumn{3}{|c|}{$\begin{array}{l}\text { Theoretical finishing time } \\
\text { (min:s) }\end{array}$} & \multicolumn{3}{|c|}{$\begin{array}{l}\text { Theoretical } \\
\text { finishing race } \\
\text { position }\end{array}$} \\
\hline & 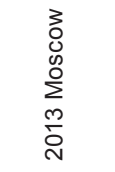 & $\begin{array}{l}\frac{0}{\tilde{r}} \\
\frac{0}{0} \\
\frac{N}{N}\end{array}$ & 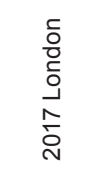 & $\begin{array}{l}3 \\
0 \\
0 \\
\infty \\
\stackrel{0}{0} \\
\stackrel{m}{0} \\
\stackrel{N}{0}\end{array}$ & $\begin{array}{l}\frac{0}{x} \\
\frac{0}{0} \\
\frac{N}{N}\end{array}$ & 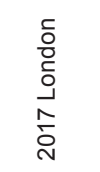 & 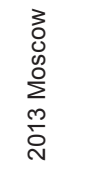 & $\begin{array}{l}\frac{0}{\alpha} \\
\frac{0}{0} \\
\frac{N}{N}\end{array}$ & 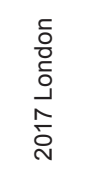 & $\begin{array}{l}3 \\
0 \\
0 \\
\infty \\
\stackrel{0}{0} \\
\stackrel{m}{0} \\
\stackrel{N}{N}\end{array}$ & $\begin{array}{l}\frac{0}{\alpha} \\
\frac{0}{0} \\
\frac{N}{N}\end{array}$ & 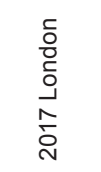 & 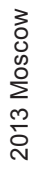 & $\begin{array}{l}\frac{0}{\alpha} \\
\frac{0}{0} \\
\frac{N}{v}\end{array}$ & $\begin{array}{l}\frac{5}{\circ} \\
\frac{0}{0} \\
\frac{1}{0} \\
\\
\text { 은 }\end{array}$ \\
\hline \multicolumn{16}{|l|}{ Men } \\
\hline 1 & $1: 43.31$ & $1: 42.15$ & $1: 44.67$ & 804.00 & 801.43 & 800.79 & 7.782 & 7.846 & 7.651 & $1: 42.80$ & $1: 41.97$ & $1: 44.57$ & 1 & 2 & 1 \\
\hline 2 & $1: 43.55$ & $1: 42.61$ & $1: 44.95$ & 804.67 & 805.30 & 802.69 & 7.771 & 7.848 & 7.648 & $1: 42.95$ & $1: 41.94$ & $1: 44.60$ & 2 & 1 & 2 \\
\hline 3 & $1: 43.76$ & $1: 42.93$ & $1: 45.21$ & 804.64 & 800.77 & 801.83 & 7.755 & 7.789 & 7.621 & $1: 43.16$ & $1: 42.83$ & $1: 44.97$ & 3 & 3 & 4 \\
\hline 4 & $1: 44.08$ & $1: 43.41$ & $1: 45.25$ & 803.93 & 800.00 & 802.92 & 7.724 & 7.736 & 7.629 & $1: 43.57$ & $1: 43.41$ & $1: 44.87$ & 4 & 5 & 3 \\
\hline 5 & $1: 44.36$ & $1: 43.55$ & $1: 45.83$ & 801.05 & 802.53 & 805.19 & 7.676 & 7.750 & 7.608 & $1: 44.22$ & $1: 43.22$ & $1: 45.15$ & 5 & 4 & 5 \\
\hline 6 & $1: 44.42$ & $1: 44.20$ & $1: 46.06$ & 800.00 & 802.36 & 803.38 & 7.661 & 7.700 & 7.575 & $1: 44.42$ & $1: 43.89$ & $1: 45.61$ & 6 & 6 & 7 \\
\hline 7 & $1: 44.79$ & $1: 46.02$ & $1: 46.30$ & 800.72 & 800.00 & 806.79 & 7.641 & 7.546 & 7.590 & $1: 44.70$ & $1: 46.02$ & $1: 45.41$ & 7 & 8 & 6 \\
\hline 8 & $1: 46.57$ & $1: 46.15$ & $1: 47.09$ & 806.45 & 807.08 & 800.00 & 7.567 & 7.603 & 7.470 & $1: 45.72$ & $1: 45.22$ & 1:47.09 & 8 & 7 & 8 \\
\hline \multicolumn{16}{|l|}{ Women } \\
\hline 1 & $1: 57.38$ & $1: 55.28$ & $1: 55.16$ & 800.23 & 800.94 & 805.96 & 6.817 & 6.948 & 6.999 & $1: 57.35$ & $1: 55.14$ & $1: 54.31$ & 3 & 1 & 1 \\
\hline 2 & $1: 57.80$ & $1: 56.49$ & $1: 55.92$ & 805.41 & 802.73 & 801.67 & 6.837 & 6.891 & 6.916 & $1: 57.01$ & 1:56.09 & $1: 55.68$ & 1 & 3 & 2 \\
\hline 3 & $1: 57.91$ & $1: 56.89$ & $1: 56.65$ & 805.27 & 808.45 & 801.77 & 6.830 & 6.916 & 6.873 & $1: 57.14$ & $1: 55.67$ & 1:56.39 & 2 & 2 & 3 \\
\hline 4 & $1: 57.95$ & $1: 57.02$ & $1: 57.54$ & 800.00 & 800.40 & 804.25 & 6.783 & 6.840 & 6.842 & 1:57.95 & $1: 56.96$ & $1: 56.92$ & 6 & 4 & 4 \\
\hline 5 & 1:58.05 & 1:57.37 & $1: 57.68$ & 801.29 & 802.86 & 801.74 & 6.788 & 6.840 & 6.813 & $1: 57.86$ & $1: 56.95$ & $1: 57.42$ & 5 & 5 & 5 \\
\hline 6 & $1: 58.21$ & 1:57.69 & $1: 58.41$ & 804.44 & 802.34 & 800.99 & 6.805 & 6.817 & 6.765 & $1: 57.56$ & 1:57.35 & $1: 58.26$ & 4 & 7 & 7 \\
\hline 7 & 1:59.79 & 1:59.10 & $1: 58.73$ & 800.97 & 806.00 & 806.32 & 6.686 & 6.676 & 6.791 & 1:59.65 & $1: 58.21$ & $1: 57.80$ & 7 & 6 & 6 \\
\hline 8 & $2: 00.59$ & $1: 59.57$ & 1:58.98 & 800.00 & 802.63 & 800.55 & 6.634 & 6.713 & 6.728 & $2: 00.59$ & $1: 59.918$ & $1: 58.90$ & 8 & 8 & 8 \\
\hline
\end{tabular}

Note. Theoretical finishing positions differing from actual finishing positions are highlighted in bold. 
Table 2. Mean ( $\pm S D$ ) changes of intermediate position, extra distance, speed relative to SB speed (\%) and dispersion between athletes

\begin{tabular}{|c|c|c|c|c|c|c|}
\hline \multirow[b]{2}{*}{ Variables } & \multirow[b]{2}{*}{ Medalists } & \multirow[b]{2}{*}{ Non-medalists } & \multirow[b]{2}{*}{$P$} & \multirow[b]{2}{*}{$\begin{array}{c}\text { Cohen's } \\
d\end{array}$} & \multicolumn{2}{|c|}{$\begin{array}{l}95 \% \mathrm{Cl} \text { for Mean } \\
\text { Difference }\end{array}$} \\
\hline & & & & & Lower & Upper \\
\hline Changes of position $200-300 \mathrm{~m}$ & $0.17 \pm 0.98$ & $-0.07 \pm 0.94$ & 0.419 & 0.243 & -0.809 & 0.343 \\
\hline Changes of position $300-400 \mathrm{~m}$ & $0.00 \pm 1.37$ & $-0.13 \pm 0.94$ & 0.691 & 0.119 & -2.273 & -0.483 \\
\hline Changes of position $400-500 \mathrm{~m}$ & $0.22 \pm 1.52$ & $-0.07 \pm 1.08$ & 0.446 & 0.229 & -0.804 & 0.537 \\
\hline Changes of position $500-600 \mathrm{~m}$ & $0.78 \pm 1.40$ & $-0.60 \pm 1.54$ & 0.003 & 0.924 & -1.359 & 0.203 \\
\hline Changes of position $600-700 \mathrm{~m}$ & $0.44 \pm 1.25$ & $-0.13 \pm 1.33$ & 0.143 & 0.444 & -1.045 & 0.467 \\
\hline Changes of position $700-800 \mathrm{~m}$ & $0.50 \pm 1.25$ & $-0.13 \pm 1.83$ & 0.202 & 0.386 & -1.619 & 0.352 \\
\hline Total changes of position on bends & $0.83 \pm 2.18$ & $-0.28 \pm 2.07$ & 0.087 & 0.522 & -2.365 & 0.165 \\
\hline Total changes of position on straights & $1.28 \pm 2.19$ & $-0.87 \pm 2.31$ & 0.003 & 0.945 & -3.507 & -0.782 \\
\hline Total changes of position & $2.11 \pm 2.08$ & $-1.13 \pm 2.96$ & $<.001$ & 1.216 & -4.845 & -1.644 \\
\hline Extra distance $200-300 \mathrm{~m}$ & $0.68 \pm 0.80$ & $0.73 \pm 0.98$ & 0.863 & 0.052 & -0.506 & 0.601 \\
\hline Extra distance $400-500 \mathrm{~m}$ & $1.16 \pm 1.11$ & $0.74 \pm 1.09$ & 0.216 & 0.374 & -1.071 & 0.249 \\
\hline Extra distance $600-700 \mathrm{~m}$ & $1.01 \pm 0.86$ & $0.88 \pm 0.91$ & 0.639 & 0.141 & -0.664 & 0.412 \\
\hline Total extra distance & $2.85 \pm 2.06$ & $2.35 \pm 2.29$ & 0.459 & 0.222 & -1.818 & 0.834 \\
\hline Time relative to SB (\%) & $100.30 \pm 0.82$ & $99.65 \pm 1.16$ & 0.042 & 0.622 & -1.283 & -0.023 \\
\hline Speed $200-300 m$ relative to SB speed (\%) & $97.57 \pm 3.74$ & $98.64 \pm 3.60$ & 0.327 & 0.296 & -1.111 & 3.268 \\
\hline Speed $300-400 \mathrm{~m}$ relative to SB speed (\%) & $96.19 \pm 2.11$ & $96.80 \pm 1.67$ & 0.275 & 0.329 & -0.500 & 1.713 \\
\hline Speed $400-500 \mathrm{~m}$ relative to SB speed (\%) & $97.65 \pm 3.08$ & $98.47 \pm 3.37$ & 0.407 & 0.250 & -1.146 & 2.779 \\
\hline Speed $500-600 \mathrm{~m}$ relative to SB speed (\%) & $101.07 \pm 1.99$ & $99.54 \pm 2.07$ & 0.016 & 0.749 & -2.751 & -0.303 \\
\hline Speed $600-700 \mathrm{~m}$ relative to SB speed (\%) & $100.44 \pm 1.26$ & $98.05 \pm 2.53$ & $<.001$ & 1.110 & -3.681 & -1.097 \\
\hline Speed $700-800 \mathrm{~m}$ relative to SB speed (\%) & $97.66 \pm 3.55$ & $93.43 \pm 5.69$ & 0.007 & 0.843 & -7.229 & -1.216 \\
\hline SS speed $200-300 m$ & $-0.38 \pm 0.95$ & $0.23 \pm 0.88$ & 0.031 & 0.665 & 0.059 & 1.148 \\
\hline SS speed $300-400 \mathrm{~m}$ & $0.06 \pm 0.98$ & $-0.03 \pm 0.94$ & 0.740 & 0.099 & -0.667 & 0.478 \\
\hline SS speed $400-500 \mathrm{~m}$ & $0.12 \pm 0.95$ & $-0.07 \pm 0.95$ & 0.517 & 0.195 & -0.757 & 0.386 \\
\hline SS speed $500-600 \mathrm{~m}$ & $0.74 \pm 0.74$ & $-0.44 \pm 0.77$ & $<.001$ & 1.553 & -1.632 & -0.722 \\
\hline SS speed $600-700 \mathrm{~m}$ & $0.76 \pm 0.46$ & $-0.46 \pm 0.86$ & $<.001$ & 1.658 & -1.668 & -0.782 \\
\hline SS speed $700-800 \mathrm{~m}$ & $0.64 \pm 0.66$ & $-0.38 \pm 0.88$ & $<.001$ & 1.268 & -1.512 & -0.540 \\
\hline
\end{tabular}

Note. $\mathrm{SS}=$ standarized score. Positive value means that speed is faster than all athletes and negative means the opposite; SB = Season's Best.

the SB speed over the 500-600 m segments onwards $(\mathrm{p}<.05)$.

Significant correlations were found between the finishing positions and total changes in intermediate positions during the race $(r=-0.64, \mathrm{p}<.001)$, total changes of intermediate positions on bends $(r=-0.52, \mathrm{p}<.001)$ and total changes of intermediate positions on straights $(r=-0.31, \mathrm{p}=.03)$. The correlation coefficients between the changes in intermediate positions and finishing positions were $r=-0.42$ $(\mathrm{p}=.003), r=-0.29(\mathrm{p}=.049)$ and $r=-0.29(\mathrm{p}=\mathrm{p} .44)$, for the $300-400-\mathrm{m}, 500-600-\mathrm{m}$ and $700-800-\mathrm{m}$ segments, respectively. The dispersion of athletes showed a negative significant correlation with the finishing position from 500-600-m onwards. The correlations coefficients were $r=-0.65(\mathrm{p}<.001)$, $r=-0.81(\mathrm{p}<.001)$ and $r=-0.73(\mathrm{p}<.001)$, for the 500-600-m, 600-700-m and 700-800-m segments, respectively. Finally, a negative correlation was found between the speed relative to the SB speed and finishing position $(r=-0.48, \mathrm{p}<.001)$.

\section{Discussion and conclusions}

The main findings of the current study were that world-class athletes ran extra distance in the 800-m finals at global championships, and this fact could slightly change the finishing positions, supporting our first hypothesis. In addition, the medalists did not cover more extra distance compared with the non-medalists, in contrast to our first hypothesis. Finally, supporting our second hypothesis, the medalists displayed higher positive changes of intermediate positions than the non-medalists, mainly because an increase in speed relative to SB from 500-m onwards whereas the non-medalists slowed down. 
A)

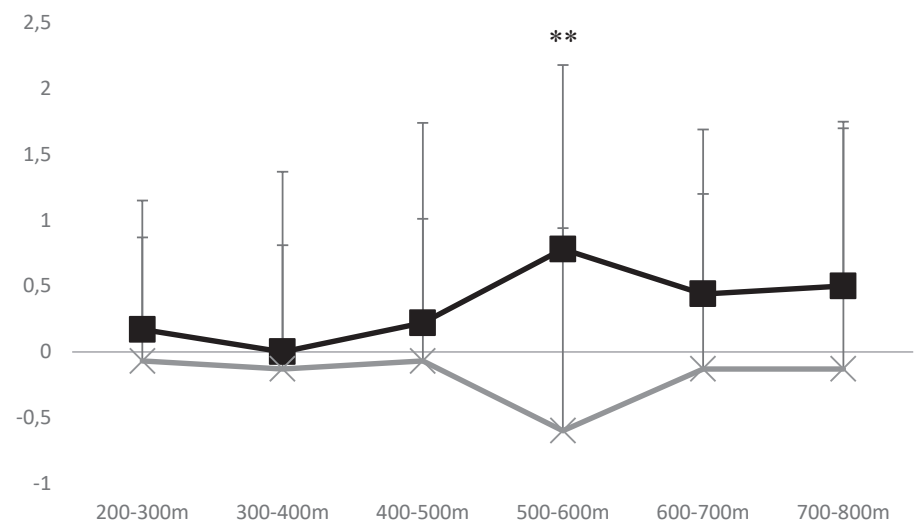

B)

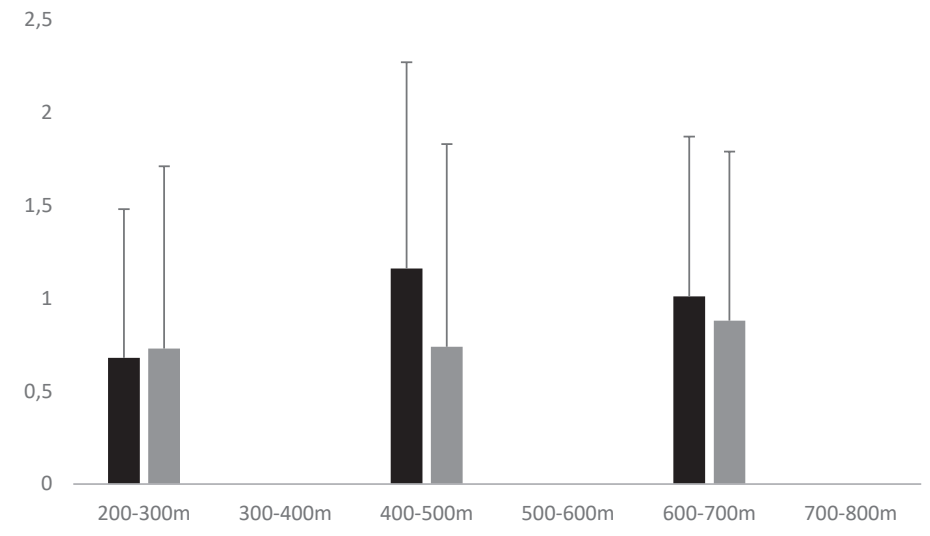

C) 104

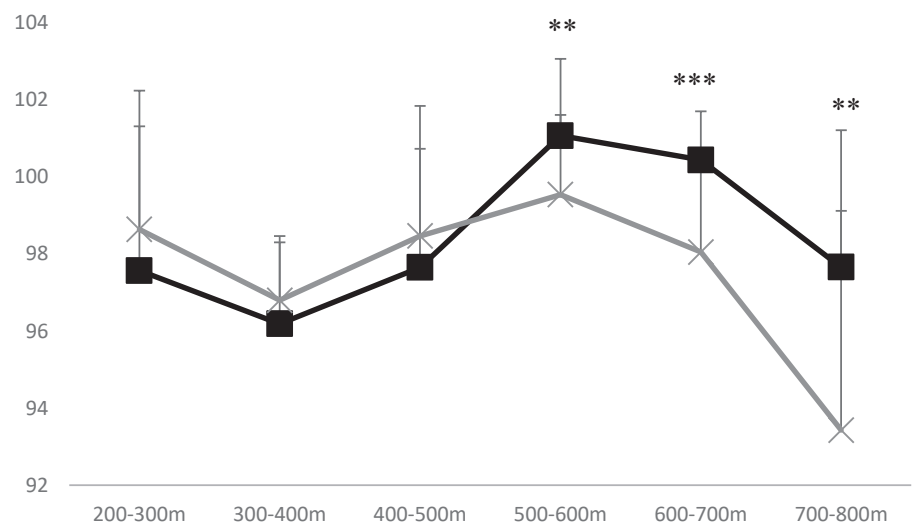

Figure 2. Changes of intermediate position per segments (A), extra distance on bends $(B)$, speed relative to $S B$ speed $(C)$. The black color refers to medalists, whereas the gray color refers to non-medalists. $p<.05^{*},<.01^{* *},<.001^{* * *}$.

In the 800 -m event, with a few bends to negotiate and the first bend run in lanes, the draw for which has been shown to have little effect on performances (Hanley, Casado \& Renfree, 2019), there were few instances where the theoretical finishing positions changed considerably from the official finishing positions. This is not to say that there was no disadvantage to running extra distance: the silver medalist in the women's race in 2013 (who ran approximately $5 \mathrm{~m}$ more than the winner) and the silver medalist in the men's race in 2016 (approximately $4 \mathrm{~m}$ more) would theoretically have won had they run shorter distances. In those cases, our findings are in agreement with those from Jones and Whipp (2002), who suggested that the middle- distance races were influenced by the distancetime curve that can be altered if the athlete ran further than the minimum distance (running wide on bends). However, in only one instance would an athlete who originally finished out of the medal positions (men's final in 2017) have gained a medal by running the theoretical shortest distance; in all other instances the small gains that were achievable with shorter running distances would have resulted in a rearranging of the medal positions, a switching of lower positions between athletes, or faster winning times. This is not to diminish the importance of running the shortest possible distance in 800 -m racing, but the results do highlight that most world-class athletes could reduce any extra distance 
run, but this requires practice as the varied pace of championship running is reflective of a more tactical approach than occurs in meet events that tend to adopt pacemakers (Filipas, Ballati, Bonato, La Torre \& Piacentini, 2018). In addition, because of the trivial to small effect sizes found between the actual vs. theoretical finishing times, and because of the high number of different observed actual finishing positions (in relation to the theoretical finishing positions) in all the events studied (Table 1), it is also important to consider that during $800-\mathrm{m}$ championship races, even very minimal finishing time differences lead to important differences in finishing positions (Hanley \& Hettinga, 2018). Therefore, the total distance covered ultimately might have some impact on finishing positions in major championship finals, which in turn represent the specific performance goal set by athletes for this type of race rather than achieving the fastest possible time. Because the total race distance is the product of running speed and time, if the athletes covered extra distance (even if only slightly), the distance-time curve is altered, and therefore, the finishing positions change (Table 1).

Regarding changes in intermediate position, the medalists displayed higher positive changes of intermediate position (gaining positions) than the non-medalists. These changes of intermediate positions occurred mainly on straights, demonstrating better tactical decision-making. In addition, the medalists tended to change race position on bends more so than the non-medalists. The greatest difference in changes in position between the medalists and non-medalists occurred in the 500-600-m (straight) segment, when the dispersion between athletes increased because of the deceleration of the non-medalists and a slight increase in speed by the medalists. The medalists were able to move up position throughout the race (without considering the first bend), although for this they had to cover more extra distance on the third and fourth bends. This reflects the fact that sometimes having to cover extra distance on bends is unavoidable if the athlete needs to overtake another athlete.

Dispersion between the medalists and nonmedalists was greater from 500-m onwards. It seems that the increase in speed observed during the last $300-\mathrm{m}$ of the race is hugely important to success in major championship 800-m finals. In agreement with the results of the present study, Hanley et al. (2019) found that, in the 800-m event, athletes increased pace from 500-m onwards. From this distance onwards, the non-medalists are unable to maintain the absolute speed of the medalists and the dispersion between them increases. These authors emphasized the importance of the endspurt in successful racing (final 200-300-m). We found that, from 500-m onwards, the speed relative to SB differed between the medalists and non-medalists allowing more gains in position by the former, whereas the non-medalists lost positions. Therefore, as González-Mohíno et al. (2020) found previously, the dispersion of athletes at the intermediate distances is a determinant of the likelihood of winning a medal. Although it is obvious that better runners (those with faster SBs, for example) are able to accelerate from 500 -m onwards more so than those with less ability, to take this right decision at this specific time does require them to make correct decisions throughout the race and has an impact on the final results.

The medalists were able to run at a higher percent of their SB speed $(100.30 \pm 0.82$ vs. 99.65 \pm 1.16 ) than the non-medalists, showing that athletes with superior absolute capabilities finished in higher positions. These data are supported by the previous study by Hanley et al. (2019), where the men's and women's medalists had finishing times $1.1 \%$ and $1.9 \%$ quicker than the non-medalists at the 2008 Olympic Games and IAAF World Championships in 2013 and 2017. Casado and Renfree (2018) observed in the preliminary rounds of the 800-m event at global championships that automatic qualifiers, fastest losers and non-qualifiers ran at similar relative SB speed in each lap and positions remained stable. In our study of finals, we found that during the first 500-m, the non-medalists ran slightly faster than the medalists. However, during the last $300-\mathrm{m}$, the medalists were able to run at speed faster than their SB, whereas the non-medalists slowed down until the end of the race, with the greatest differences in speed occurring on the last bend (600-700-m). This last finding highlights that although the bends can be responsible for adding total distance to how far an athlete races, being able to overtake on the last bend is important to overall race position.

In summary, this study demonstrates that worldclass athletes run farther than the minimum distance in championship 800-m races, and this influence finishing times and positions in some cases. Thus, we highlight the importance of running the shortest possible distance in the 800-m event. In addition, the medalists displayed higher positive changes in intermediate positions than the non-medalists (mainly on straights and to a lesser extent on the bends). The medalists are able to gain positions with extra distance on the bends, mainly because they are able to accelerate during the final $300-\mathrm{m}$ while the non-medalists slow down. The current findings indicated that run the shortest distance on the bends and be able to accelerate during the last $300-\mathrm{m}$ of the race will positively influence the final position in major championships 800-m finals. 


\section{References}

Aftalion, A., \& Martinon, P. (2019). Optimizing running a race on a curved track. PLoS ONE, 14, e0221572. doi: 10.1371/journal. pone.0221572

Aragón, S., Lapresa, D., Arana, J., Anguera. M.T., \& Garzón, B.T. (2016). Tactical behaviour of winning athletes in major championship 1500-m and 5000-m track finals. European Journal of Sport Science, 16(3), 279-286. doi: 10.1080/17461391.2015.1009494

Casado, A., Hanley, B., Jiménez-Reyes, P., \& Renfree, A. (2020). Pacing profiles and tactical behaviors of elite runners. Journal of Sport and Health Science, 10(5), 537-549. doi: 10.1016/j.jshs.2020.06.011

Casado, A., \& Renfree, A. (2018). Fortune favors the brave: Tactical behaviors in the middle-distance running events at the 2017 IAAF World Championships. International Journal of Sports Physiology and Performance, 13(10), 1386-1391. doi: 10.1123/ijspp.2018-0055

Casado, A., Renfree, A., Maroto-Sánchez, B., \& Hanley, B. (2020). Individual performances relative to season bests in major track running championship races are distance-, position- and sex-dependent. European Journal of Human Movement, 44, 146-161.

Cohen, J. (1988). Statistical power analysis for the behavioural sciences (2nd ed.). Hillsdale, NJ: Lawrence Erlbaum.

Filipas, L., Ballati, E.N., Bonato, M., La Torre, A., \& Piacentini, M.F. (2018). Elite male and female 800-m runners display different pacing strategies during seasons best performances. International Journal of Sports Physiology and Performance, 13, 1364-1348. doi: 10.1123/ijspp.2018-0137

González-Mohíno, F., del Cerro, J.S., Renfree, A., Yustres, I., \& González-Ravé, J.M. (2020). The relationship between tactical positioning and the race outcome in 800-m running at the 2016 Olympic Games and 2017 IAAF World Championship. Journal of Human Kinetics, 71(1), 299-305. doi: 10.2478/hukin-2019-0090

Hanley, B., Casado, A., \& Renfree, A. (2019). Lane and heat draw have little effect on placings and progression in Olympic and IAAF World Championship $800 \mathrm{~m}$ running. Frontiers in Sports and Active Living, 1, 19. doi: 10.3389/fspor.2019.00019

Hanley, B., \& Hettinga, F.J. (2018). Champions are racers, not pacers: An analysis of qualification patterns of Olympic and IAAF World Championship middle distance runners. Journal of Sports Science, 36, 2614-2620.

Hanley, B., Stellingwerff, T., \& Hettinga, F.J. (2019). Successful pacing profiles of Olympic and IAAF World Championship middle-distance runners across qualifying rounds and finals. International Journal of Sports Physiology and Performance, 14(7), 894-901. doi: 10.1123/ijspp.2018-0742

Hopkins, W.G., Marshall, S.W., Batterham, A.M., \& Hanin, J. (2009). Progressive statistics for studies in sports medicine and exercise science. Medicine and Science in Sports and Exercise, 41, 3-12. doi: 10.1249/MSS.0b013e31818cb278

Jones, A.M., \& Whipp, B.J. (2002). Bioenergetic constraints on tactical decision making in middle distance running. British Journal of Sports Medicine, 36, 102-104. doi: 10.1136/bjsm.36.2.102.

Martin, D.E., \& Coe, P.N. (1997). Better training for distance runners (2nd ed.). Champaign, IL: Human Kinetics.

Mytton, G.J., Archer, D.T., Turner, L., Skorski, S., Renfree, A., Thompson, K.G., \& St Clair Gibson, A. (2015). Increased variability of lap speeds: Differentiating medalists and non-medalists in middle-distance running and swimming events. International Journal of Sports Physiology and Performance, 10, 369-373. doi: 10.1123/ijspp.2014-0207

Renfree, A., \& Casado, A. (2018). Athletic races represent complex systems, and pacing behavior should be viewed as an emergent phenomenon. Frontiers in Physiology, 9, 1432. doi: 10.3389/fphys.2018.01432

Renfree, A., Martin, L., Micklewright, D., \& St Clair Gibson, A. (2014). Application of decision-making theory to the regulation of muscular work rate during self-paced competitive endurance activity. Sports Medicine, 44, 147-158. doi: 10.1007/s40279-013-0107-0

Renfree, A., Mytton, G.J., Skorski, S., \& St Clair Gibson, A. (2014). Tactical considerations in the middle distance running events at the 2012 Olympic Games. International Journal of Sports Physiology and Performance, 9 , $362-364$.

World Athletics. (2019). Track and field facilities manual. Monte Carlo: World Athletics.

Submitted: January 20, 2021

Accepted: October 18, 2021

Published Online First: December 6, 2021

Correspondence to:

Fernando González-Mohíno, Ph.D.

Facutly of Sport Science, Sport Training Laboratory,

University of Castilla-La Mancha, Toledo, Spain.

Universidad Nebrija, Facultad de Ciencias de la Vida

y de la Naturaleza, Madrid, Spain.

E-mail: fernando.gmayoralas@uclm.es 